\title{
Water Dynamics in Cement Paste at Early Age Prepared with Pozzolanic Volcanic Ash and Ordinary Portland Cement using Quasielastic Neutron Scattering
}

\author{
Kunal Kupwade-Patil ${ }^{1}$, Madhusudan Tyagi ${ }^{2,3}$, Craig M. Brown $^{2,4}$ and Oral Büyüköztürk ${ }^{1}$ \\ ${ }^{1}$ Laboratory for Infrastructure Science and Sustainability (LISS), Department of Civil and \\ Environmental Engineering, Massachusetts Institute of Technology, Cambridge, MA 02139, USA \\ Corresponding Author's Email: kunalk@mit.edu and obuyuk@mit.edu ; Tel: 001-(617)-253-7186 \\ ${ }^{2}$ NIST Center for Neutron Research (NCNR), National Institute of Standards and Technology, \\ Gaithersburg, MD 20899, USA \\ ${ }^{3}$ Department of Materials Science and Engineering, University of Maryland, College Park, MD \\ 20742, USA \\ ${ }^{4}$ Department of Chemical and Biomolecular Engineering, University of Delaware, Newark, DE \\ 19716, USA
}

\begin{abstract}
Early age hydration kinetics of Portland cement with pozzolanic volcanic ash was examined using quasielastic neutron scattering. Volcanic ash consisting of two different particle sizes was used to prepare cement pastes with different ratios of Portland cement to volcanic ash. The concentration of the volcanic ash played a major role in the bound water index and self-diffusion coefficients of hydration water confined in the cement paste. An increase in the particle size of the volcanic ash affected the degree of hydration by allowing more free and mobile water in the gel pores, suggesting that volcanic ash may not have completely reacted during the experimental time frame. This study shows that the particle size along with variation in volcanic ash composition governs the early age hydration process in volcanic ash cements.
\end{abstract}

Keywords: Portland cement, Volcanic Ash; Quasielastic Neutron Scattering; Hydration; Diffusion

\section{Introduction}

Supplementary cementitious materials such as volcanic ash are used in the cement industry to effectively utilize waste materials in developing durable and engineered cementitious concretes 
$[1,2]$. In addition, this helps in reducing the carbon foot-print by lowering the energy consumption along with enhanced environmental benefits and cost reduction. Volcanic ash (VA) is a locally available material that has been historically used as an additive in cementitious materials to create durable and sustainable concretes $[3,4]$. The Romans took the first initiative for using lime and natural pozzolans to prepare cements that were used to build the Bay of Naples $[4,5]$. They finely ground the volcanic rocks and mixed the powder with lime and sand to produce mortars of high strength and durability that could survive in brackish environments. However, not all volcanic rocks are effective since only some have sufficient amorphous content to produce a pozzolanic reaction $[1,6]$. The inclusion of volcanic ash containing a high alumina content leads to the formation of a binder phase known as calcium-alumino-silicate-hydrate (C-A-S-H) gel, and when carefully used in correct proportions can lead to a high strength concrete material $[3,7,8]$.

A variety of surface and bulk characterization techniques have been used to examine the hydration of Portland cement [9]. Hydration in cements is a complex process and in-situ experiments including nuclear magnetic resonance (NMR), small angle neutron/X-ray scattering, and Raman spectroscopy are commonly used to study the hydration mechanism in Portland cements. Although, these techniques are useful in deciphering the morphological and structural details of cementitious gels; the insight into the role of water during hydration cannot be unraveled. There exist a limited number of characterization techniques suitable for tracking the speciation and role of water during hydration. For instance, ${ }^{1} \mathrm{H}$ NMR relaxometry has occasionally been used for over three decades; a recent set of studies by Valori et al[10] and Muller et al. [11] provide insight into cement pore-water interactions inside the cementitious gels. These studies discuss techniques for measuring water in different pore sizes along with the specific surface area and density of C-S-H 
hydrates including gel and capillary pores. An additional technique, inelastic neutron scattering (INS) and quasielastic neutron scattering (QENS) have been used to study the early age kinetics and degree of hydration reaction of $\mathrm{C}_{3} \mathrm{~S}, \mathrm{C}_{2} \mathrm{~S}$ and C-S-H pastes [7, 12-14]. Although, both NMR and neutron scattering techniques use bulk-scale analysis and use signals from protons, the timescale of measurements with INS and QENS is superior compared to that of NMR. The energy measured using QENS/INS reflects times in pico-second to femto-second ranges, respectively, while NMR data provides timescales in the millisecond range[7].

QENS is a powerful experimental technique to examine the water dynamics of cement paste during the hydration process [7]. As the cement hydrates, the free water interacts chemically and/or physically in the cementitious matrix forming a glue or gel, which leads to an amorphous phase along with certain crystalline products. QENS helps to identify the transition of water from a free or mobile state to an immobile state during the hydration process [15]. The immobile water is encapsulated in the form of chemically bound water inside the calcium- silicate-hydrate (C-S-H) which is the binding gel in the cement matrix system. The immobile water inside the gel pores ( 2 to $\sim 5 \mathrm{~nm}$ ) can be constrained or pseudo-bound, but the water at the interlayer is usually chemically bound [16].

Several studies have used QENS to understand the metamorphosis of multiphase mechanisms which evolve during the hydration process of tricalcium silicates $\left(\mathrm{C}_{3} \mathrm{~S}\right)$ [17-20], Ordinary Portland Cement (OPC) [21] and incorporation of alumino-silicate sources such as fly ash or ground granulated blast furnace slag (GGBFS) in OPC [21-29]. Bulk water present in the cement matrix is associated with free water in capillary pores and large gel pores, whereas the restricted water is attributed to constrained water where the mobility of water is limited, since it is present inside small gel pores. Chemically bound water is related to the "structural water" present in C-S-H 
which is a hydration product of OPC based system [17]. Because the neutron signal is largely dominated by hydrogen, the observed immobile molecules are mostly representative of the chemically bound water. Details regarding the calculation of the free and constrained water are characterized by a bound-water index (BWI), the definition of which can be found elsewhere $[7$, $13,22]$, and has been used as an indicator to characterize the early age kinetics of hydrating cementitious systems. Although, to date, limited studies have been performed with supplementary cementitious additives such as the superplasticizer and GGBFS using QENS [24, 30], the existing studies using silica fume blend with OPC possesses similarities to volcanic ash additives as both help to densify the matrix and reduce the porosity while increasing the compressive strength of the matrix $[3,4,31,32]$.

Recent experiments on cement paste using QENS examining the reactivity and dynamics of water molecules bound in the C-S-H gel pore were conducted by Li et al., 2015 [30], and complementary molecular dynamics (MD) modeling was performed by Hou et al., 2015[33]. This work used MD simulations with reactive force fields to understand the structure, reactivity and dynamics of water molecules confined in the C-S-H gel nanopores (4 to $5 \mathrm{~nm}$ in width). The results showed that due to highly reactive C-S-H surface, hydrolytic reactions take place at the solid liquid interface, thus adsorbing water molecules and transforming $\mathrm{Si}-\mathrm{OH}$ and $\mathrm{Ca}-\mathrm{OH}$ chemical groups to be infused in the C-S-H gel structure. Additionally, the stable H-bonds are interconnected with $\mathrm{Ca}-\mathrm{OH}$ and $\mathrm{Si}$ $\mathrm{OH}$ groups thus limiting the mobility of the surface water molecules inside the C-S-H gel. Effect of additives along with the translational and rotational dynamics of water in OPC pastes cured for 7, 14 and 30 days were examined using QENS[30]. A polycarboxylate-based superplasticizer helped in confining the mobile water in the C-S-H gel pore that led to the reduction in self-diffusion coefficients and mean jump distance of water molecules. Additionally, the additive 
helped in the early age evolution of the cement pastes thus forming a uniform and homogenous mixture, which was evaluated using BWI and mean jump distance of the water molecules.

The work we present here details the effect of ash particle size and concentration of volcanic ash when volcanic ash is used as a partial substitute to Portland cement. The objective of this research was to examine the water dynamics of hydrating Portland cement by varying the concentration and threshold particle size of volcanic ash using QENS.

\section{Materials and Methods}

\subsection{Raw Material Characterization}

Finely ground volcanic ash was procured from Akhal Province, Saudi Arabia. ${ }^{\dagger}$ Volcanic ash was ground into two different particle sizes using a planetary ball mill. Particle size distribution was performed on the volcanic ashes and Portland cement by suspending them in isopropyl alcohol using the Laser Light Scattering technique with a Micromeritics Saturn DigiSizer 5205. The mean particle size of the volcanic ashes of $17.14 \mu \mathrm{m}$ and $14.48 \mu \mathrm{m}$ is designated as IP and FA, respectively (Refer to Table 1).

Table 1. Particle size analysis for the volcanic ashes with two different particle sizes

\begin{tabular}{ccccccc}
\hline Nomination & $\begin{array}{l}\text { Mean } \\
(\mu \mathrm{m})\end{array}$ & $\begin{array}{l}\text { Median } \\
(\mu \mathrm{m})\end{array}$ & $\begin{array}{l}\text { Mode } \\
(\mu \mathrm{m})\end{array}$ & \multicolumn{2}{l}{$\begin{array}{l}\text { Diameter for Selected percentiles by } \\
\text { volume }\end{array}$} \\
\cline { 5 - 7 } & & & & $\mathrm{D} \mathrm{90}(\mu \mathrm{m})$ & $\mathrm{D} 50(\mu \mathrm{m})$ & $\mathrm{D} 10(\mu \mathrm{m})$ \\
\hline IP & 17.14 & 10.00 & 13.27 & 42.46 & 10.00 & 1.50 \\
FA & 14.48 & 9.80 & 14.92 & 34.27 & 9.80 & 1.49 \\
OPC & 12.73 & 7.94 & 6.65 & 30.10 & 7.94 & 2.12 \\
\hline
\end{tabular}

${ }^{\dagger}$ Certain commercial equipment, instruments, or materials are identified in this paper to foster understanding. Such identification does not imply recommendation or endorsement by the National Institute of Standards and Technology, nor does it imply that the materials or equipment identified are necessarily the best available for the purpose. 
The chemical composition of OPC and volcanic ash was measured using X-Ray fluorescence (XRF) spectroscopy and the results are shown in Table 2. The sum of silicon oxide $\left(\mathrm{SiO}_{2}\right)$, aluminum oxide $\left(\mathrm{Al}_{2} \mathrm{O}_{3}\right)$ and ferric oxide $\left(\mathrm{Fe}_{2} \mathrm{O}_{3}\right)$ components for the raw VA is $64.3 \%$, indicating that the material is a Class C type of ash according to ASTM C 618[34].

Table 2. Chemical composition of OPC and Volcanic Ash

\begin{tabular}{|c|c|c|c|c|c|c|c|c|c|c|c|}
\hline \multirow{2}{*}{$\begin{array}{c}\text { Binder } \\
\text { Type }\end{array}$} & \multicolumn{11}{|c|}{ Chemical Composition (mass \% as oxide) } \\
\hline & $\mathrm{CaO}$ & $\mathrm{SiO}_{2}$ & $\mathrm{Al}_{2} \mathrm{O}_{3}$ & $\mathrm{MgO}$ & $\mathrm{SO}_{3}$ & $\mathrm{TiO}_{2}$ & $\mathrm{~K}_{2} \mathrm{O}$ & $\mathrm{Fe}_{2} \mathrm{O}_{3}$ & $\mathrm{Na}_{2} \mathrm{O}$ & $\mathrm{MnO}$ & $\mathrm{SrO}$ \\
\hline $\mathrm{OPC}$ & 62.27 & 16.73 & 3.63 & 1.22 & 3.92 & 0.24 & 0.62 & 3.28 & 0.34 & 0.06 & 0.07 \\
\hline $\begin{array}{l}\text { Volcanic } \\
\text { Ash }\end{array}$ & 9.08 & 38.79 & 13.01 & 6.18 & 0.12 & 2.34 & 1.21 & 12.31 & 3.32 & 0.18 & 0.03 \\
\hline
\end{tabular}

\subsection{Mixing}

Initial dry mixing of the VA and OPC was performed using a Daigger vortex-genie 2 mixer (model no. G560) at $335 \mathrm{rad} / \mathrm{s}$ (3200 rpm). This mixing helped ensure that ash was uniformly mixed with the Portland cement prior to exposure to de-ionized water. For convention, we labelled each sample based on the mean particle size and corresponding weight percentage of the volcanic ash. Therefore, a sample with $50 \mathrm{wt} \%$ VA with $17.14 \mu \mathrm{m}$ (IP) and $50 \mathrm{wt} \%$ OPC is referred to as IP-50, while the similar combination prepared with $14.48 \mu \mathrm{m}$ is referred to as FA-50 (refer to Table 3).

Table 3. Composition of Volcanic Ash and Portland Cement Pastes

\begin{tabular}{llll}
\hline \multicolumn{3}{c}{ Weight Percent (\%) } \\
\hline Sample & Portland Cement & $\begin{array}{l}\text { Volcanic Ash } \\
(\text { mean dia }=17 \mu \mathrm{m})\end{array}$ & $\begin{array}{l}\text { Volcanic Ash } \\
(\text { mean dia=14 } \mu \mathrm{m})\end{array}$ \\
\hline OPC & 100 & 0 & 0 \\
IP-10 & 90 & 10 & 0 \\
IP-50 & 50 & 50 & 0 \\
FA-10 & 90 & 0 & 10 \\
FA-50 & 50 & 0 & 50 \\
\hline
\end{tabular}

All samples were mixed with a constant water to cement ratio of 0.55 by mass. The samples were mixed near the experiment station and exposed to beam within 2 minutes of mixing. The cement 
paste was sandwiched between aluminum foil and pressed against an annular mold to ensure uniform thickness and to give a cylindrical shape.

\subsection{Neutron Scattering Experiments}

In-situ experiments on cement pastes were conducted at room temperature on the high flux backscattering spectrometer (HFBS) and disk chopper spectrometer (DCS) at the national institute of standards and technology (NIST) Center for Neutron Research (NCNR)[35]. The experimental data on HFBS was measured by $16 \mathrm{He}^{3}$ detectors, and the corresponding scattering vector, $Q$, lies between values of $0.25 \AA^{-1}$ to $1.75 \AA^{-1}$. The energy resolution of HFBS is $0.8 \mu \mathrm{eV}$ with a dynamic range of $\pm 16 \mu \mathrm{eV}$, which allows the dynamics of water molecules in the time range from $0.1 \mathrm{~ns}$ to 4 ns to be measured. The DCS is a general purpose direct geometry time of flight spectrometer, which uses seven synchronized disk choppers spinning at high speed to produce a pulsed monoenergetic neutron beam [36]. Energies of the scattered neutrons are measured by their individual time-of-flight over a fixed distance of $4.01 \mathrm{~m}$. The incident monochromatic neutron wavelength Was $9.0 \AA$ (1.01 meV), which results in an energy resolution of full width half maximum (FWHM) of about $20 \mu \mathrm{eV}$. The detectors were grouped to obtain a set of five spectra in the $Q$ range from $0.31 \AA^{-1}$ to $1.22 \AA^{-1}$. A DCS annular sample can of inner diameter $17.8 \mathrm{~mm}$ and height of $110 \mathrm{~mm}$ were used for this experiment. The pre-weighed cement paste was sandwiched in a thin aluminum foil, which was then rolled into an annulus having the same inner circumference of the cylindrical sample holder. Sample height was about $90 \mathrm{~mm}$ (foil), and we used beam mask of $80 \mathrm{~mm}$ x 17.5 $\mathrm{mm}$. The samples were prepared in annular sample cans to have about $10 \%$ of scattering and to minimize effects of multiple scattering. No multiple scattering corrections to the data were performed. All the experiments were performed at the guide hall ambient temperature of $23{ }^{0} \mathrm{C}$. 
The temperature at the sample was recorded over time to be $23 \pm 0.2^{\circ} \mathrm{C}$ and monitored using a Lakeshore temperature controller with a reported accuracy of $0.1 \mathrm{~K}$.

The data reduction and modeling of the data was performed in the DAVE software environment [37]. The QENS spectrum, $\mathrm{S}(\mathrm{Q}, \omega)$, as a function of $\mathrm{Q}$ and energy transfer, $\omega$, as measured by DCS was modeled using four components as shown in Equation No. $1[17,18]$, comprising of a background term $\mathrm{C}_{0}$, which is the fixed baseline intensity, and the terms of $\mathrm{A}$ and $\mathrm{B}$. A is the scattered elastic intensity within the instrumental resolution that is associated with the chemically bound (CB) hydrogen atoms or also commonly known as "structural water" [17], $\mathrm{B}_{1}$ is the number density of free hydrogen atoms as in the bulk water, $\Gamma_{1}$ is the Lorentzian half-width at half maximum (HWHM) for the bulk water component, $\mathrm{B}_{2}$ is the number density of hydrogen atoms in pseudo-bound or constrained form, $\Gamma_{2}$ is the second lorentzian with the variable HWHM fitting parameter, and $\mathrm{R}(Q, \omega)$ is the instrument resolution for which a vanadium standard was used.

$$
\mathrm{S}(\mathrm{Q}, \omega)=\mathrm{C}_{\mathrm{o}}+\left(\mathrm{A} \delta(\omega=0)+\mathrm{B}_{1}\left[\frac{\Gamma_{1}}{\pi\left(\Gamma_{1}^{2}+\omega^{2}\right)}\right]+\mathrm{B}_{2}\left[\frac{\Gamma_{2}}{\pi\left(\Gamma_{2}^{2}+\omega^{2}\right)}\right]\right) \otimes \mathrm{R}(\mathrm{Q}, \omega)
$$

For QENS data collected on HFBS, the above model was used with the background term fixed at zero. From the above model, the bound water index (BWI) can be calculated which is the relative amount of immobile hydrogens and is determined by,

$$
\mathrm{BWI}=\frac{\mathrm{A}+\mathrm{B}_{2}}{\mathrm{~A}+\mathrm{B}_{1}+\mathrm{B}_{2}}
$$

where $\mathrm{A}+\mathrm{B}_{2}$ gives the total bound water in the hydrating paste. The three component model (elastic and two Lorentzians) allows three population of hydrogen [immobile-hydrogen in cement paste 
(A), freely diffusing water $\left(\Gamma_{1}\right)$, and constrained-water $\left.\left(\Gamma_{2}\right)\right]$ in the cement paste to be tracked over the course of hydration as function of time.

A sample fit using three-component model of QENS data at $\mathrm{Q}=0.49 \AA^{-1}$ was obtained on IP-50 via DCS after three hours of hydration is shown in Figure 1. The data was averaged over each hour. The blue dotted line represents the elastic contribution while the solid black line represents the total fit and the dashed lines represent the Lorentzian functions for modeling the data. We would like to clarify that even though two lorentzian (free and pseudo bound) are used to model the data and to calculate bound water index for the sake of discussion, in this manuscript we are primarily concerned with free water lorentzian which relates to the diffusion motion of the water molecules. 


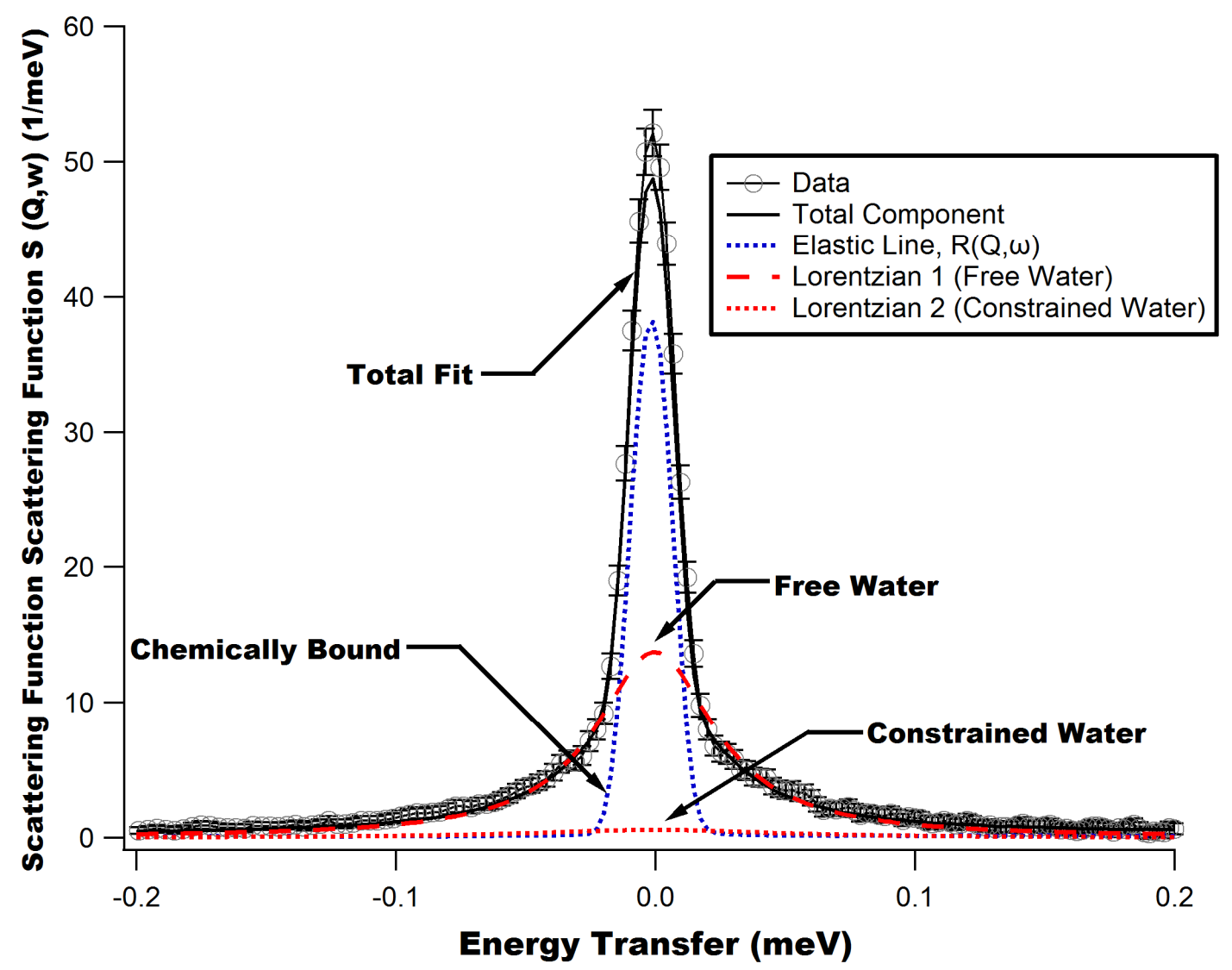

Fig 1. Typical fitting of the QENS data (grey circles, error bars indicate one standard deviation based on counting statistics) at 3 hours of hydration time for IP-50 using DAVE [37], detailing the instrument resolution and double Lorentzian profiles as dotted lines. The overall fit is indicated by the black solid line.

\section{Results and Discussion}

A plot of the QENS data for OPC with 0.55 water to cement ratio measured over 15 hours (900 mins) is shown in Figure 2A. To obtain each value at every hour the data was summed over all Q values $\left(0.16 \AA^{-1}, 0.29 \AA^{-1}, 0.49 \AA^{-1}, 0.70 \AA^{-1}, 0.901 .10 \AA^{-1}\right.$ and $\left.1.24 \AA^{-1}\right)$. During the early period of hydration, as soon as the water comes in contact with the cement mixture various hydration products start forming. As the hydration process continues, the water changes state from free to immobile due to the evolution of the cementitious matrix. The main feature in the data is the prominent increase in elastic intensity with time which is associated with the nucleation and growth stage where increasingly higher amount of hydrogen is bound in the interlayer C-S-H gel 
along with its secondary hydration products including ettringite and portlandite $[22,38]$. The observed decrease in the broad Lorentzian intensity, and development of a narrow Lorentzian with time also indicates the conversion from free water to pseudo-bound hydrogen related to the development of small gel pores and finally leading to bound water with setting of the cement paste (see Figure 2B). It has been shown that final setting time from free to constrained water in the cement paste depends on the chemical composition of the binder/admixture which forms various microstructural products, particle size of the products and the interaction forces developed at the solid/water interface [18, 22, 39].
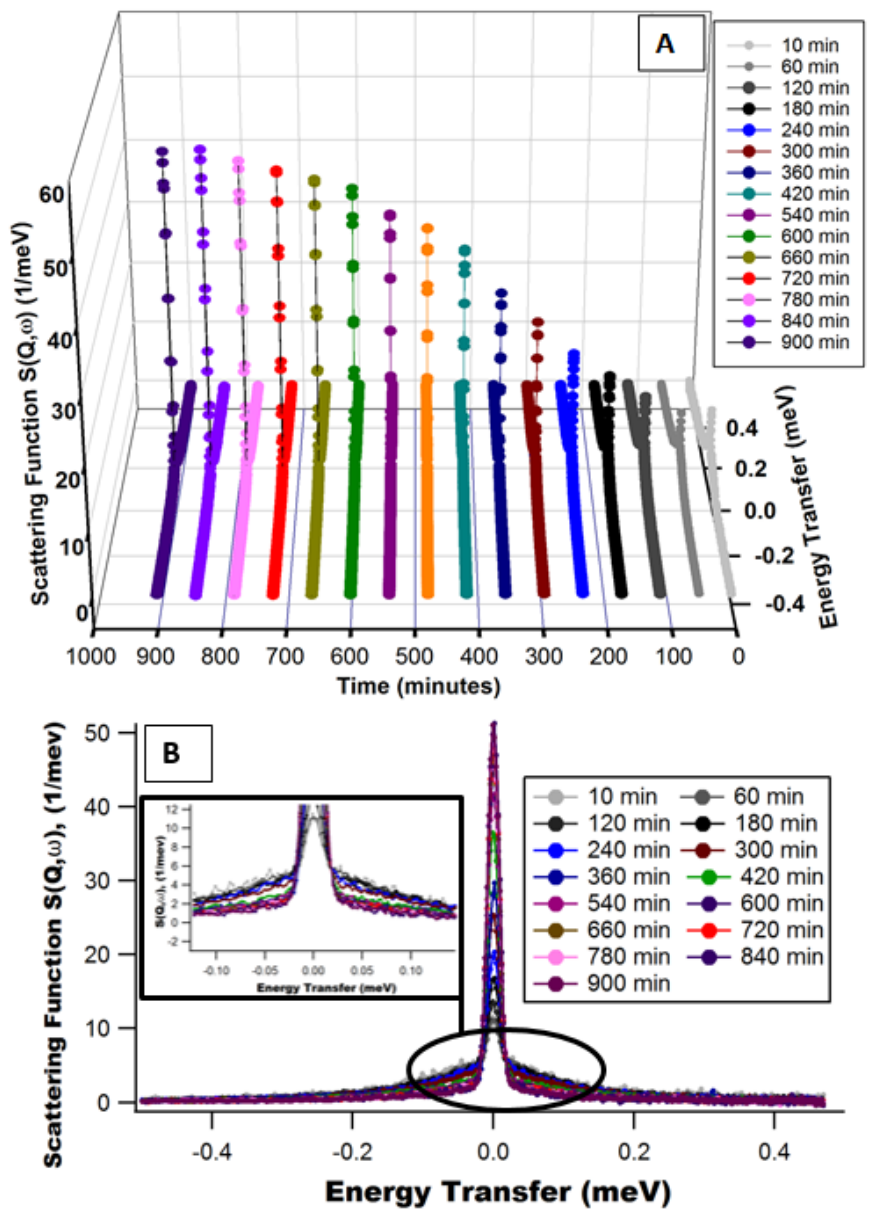

Fig 2. A) QENS spectra obtained on DCS for hydrating cement for 15 hours prepared with OPC and 0.55 water to cement ratio. Solid line through the data points is the fit to the data as detailed in the text. The data was summed over all $Q$ values $\left(0.16 \AA^{-1}, 0.29 \AA^{-1}, 0.49 \AA^{-1}, 0.70 \AA^{-1}, 0.90\right.$ $1.10 \AA^{-1}$ and $1.24 \AA^{-1}$ ). B) 2D plot exhibiting broadening with hydration time 
Figure 3 represents the scattering function $\mathrm{S}(Q, \omega)$ for OPC plotted against scattering vector $Q$ after 1 hour of hydration. The broadening of the spectra increases strongly with increasing $Q$ values. Qualitatively this suggests that the motions are diffusive and are originating from bulk-like water. The intensity of the elastic line generally decreases as a function of $Q$. The QENS diffusion/rotation intensity usually goes through a maximum and then decreases, like a shark fin. Also, at different $Q$ values different diffusion motions occur and the widths are proportional to the $Q^{2}$ of the lorentzians.

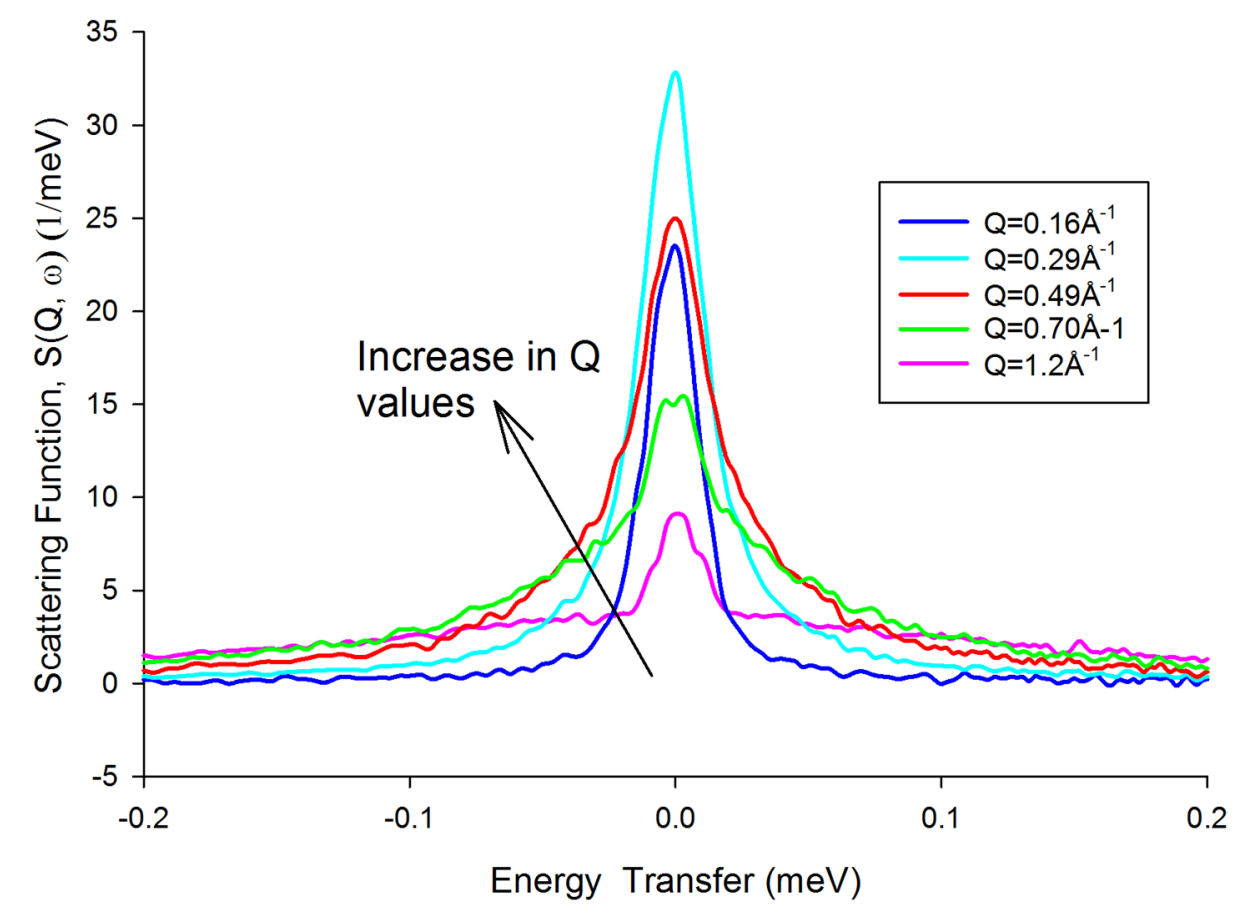

Fig 3. QENS Spectra indicating broadening with increase in $Q$ values for OPC after 1 hour of hydration

BWI for OPC and combinations of volcanic ash /OPC for the first 15 hours of hydration is shown in Figure 4. To obtain BWI values the data was summed over all $Q$ values $\left(0.16 \AA^{-1}, 0.29 \AA^{-1}, 0.49\right.$ $\AA^{-1}, 0.70 \AA^{-1}, 0.90 \AA^{-1}, 1.10 \AA^{-1}$ and $\left.1.24 \AA^{-1}\right)$. All specimens showed a steady rise in BWI up to about 300 minutes, which can be attributed to the standard kinetic profile for hydration of 
cementitious materials, though without an apparent induction period given the time resolution of this data. After about 300 minutes of hydration, OPC, FA-10 and IP-10 showed higher BWI compared to IP-50 and FA-50 showing clearly the effect of ash particle size and its concentration on the kinetics of the cement paste. It is interesting to see that after 600 minutes of completion of hydration, 50\% substitution of volcanic ash compositions (IP-50 and FA-50) showed lower BWI by a factor of $\approx 2$ as compared to OPC, FA-10 and IP-10 combinations. Normal understanding is that a finer particle size of the volcanic ash leads to the formation of more amounts of hydration products which in turn corresponds to a higher BWI, which is in agreement with previous studies $[15,18]$. Clearly, the effect of concentration of volcanic ash substitution is playing a major role in controlling the BWI. However, the BWI is higher for IP-10 as compared to FA-10, while it is slightly lower in FA-50 than in IP-50. At $10 \%$ substitution the fine volcanic ash $(\mathrm{FA}=14.48 \mu \mathrm{m})$ acts as pozzolanic filler, whereas when slightly larger sized particles $(\mathrm{VA}=17.14 \mu \mathrm{m})$ are substituted for OPC the amount of alumina involvement is higher on the ash and may have contributed to greater BWI as compared to FA-10. Also, the chemically bound water inside the C$\mathrm{S}-\mathrm{H}$ is influenced by the variation in alumina, silica and calcium from the volcanic ash. At $50 \%$ substitution the volcanic ash acts as a partial substitute to OPC, and all of the volcanic ash does not get involved in the early stage of hydration thus leading to lower BWI. Additionally, different levels of grinding the volcanic ash leads to difference in the amorphous content, which in turn influences the BWI. Further studies using differential scanning calorimetry (DSC) for evaluating hydration rates along with small angle neutron scattering (SANS) is required to examine the structure of the resulting hydration products.

The effect of BWI on $\mathrm{C}_{3} \mathrm{~S}$ and Portland cements is well known $[13,15,17-19,40]$, whereas the influence of Supplementary Cementitious Materials (SCM's) on BWI is an ongoing area of 
research. SCM's such as fly ash, volcanic ash, GGBFS and silica fume are used as admixtures or a partial substitutes for Portland cement, that lead to alterations in the chemical structure of the hydration products and impacts the microstructure which in turn influences the BWI. The interaction of these hydration products during curing can lead to leaching of calcium in the C-S-H gel, while dissipating some remnants of unreacted volcanic ash thus increasing the free water content in the system.

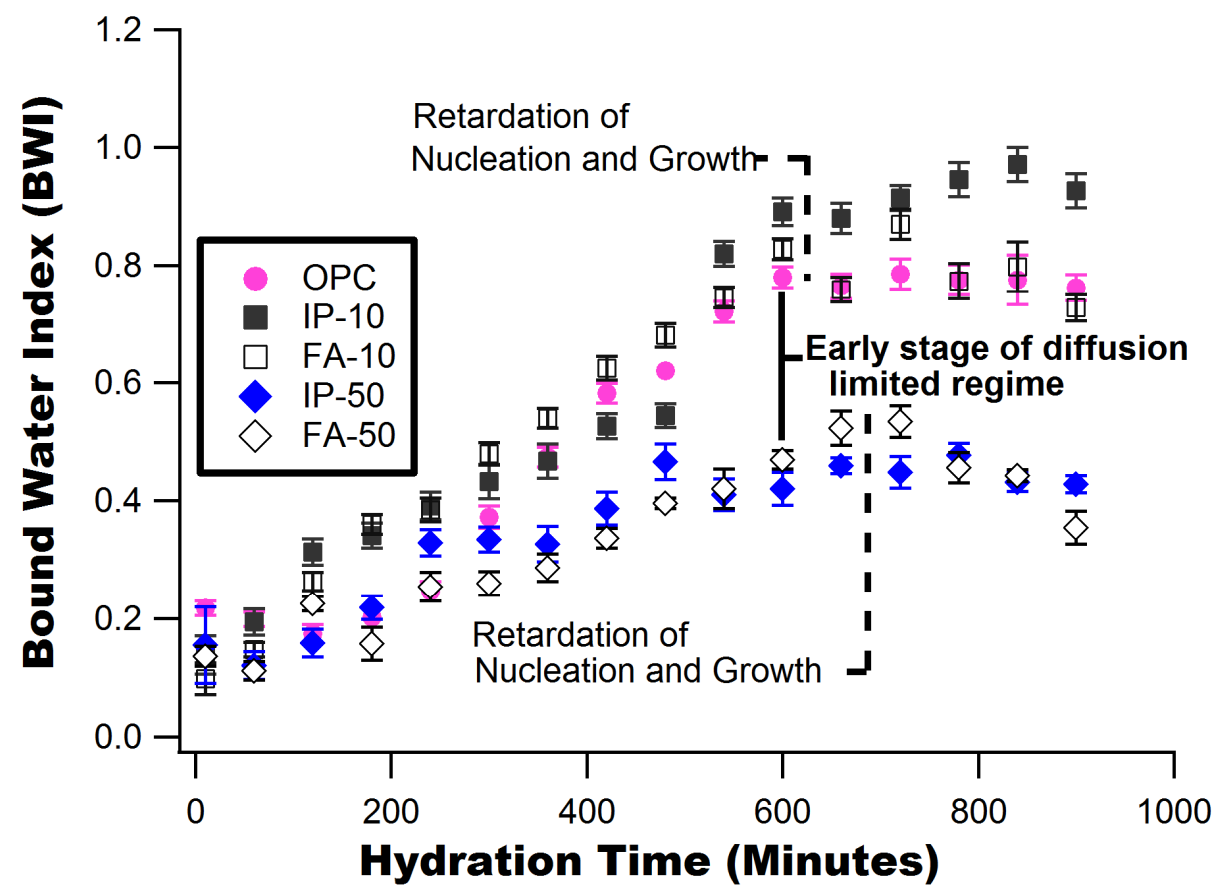

Fig 4. Bound Water Index (BWI) over 15 hours of hydration with Portland cement and combinations of Portland cement and Volcanic ash with 17 micron threshold diameter (IP) and 14 micron threshold diameter (FA) and 0.55 water to cement ratio with $|\mathrm{Q}|=0.7 \AA^{-1}$

Effect of particle size on BWI can be clearly seen by comparing IP-10 and FA-10 (see Figure 4).

For first 600 minutes both samples seem to show very similar BWI values. However, after 600 minutes of hydration, IP-10 shows an increase in BWI value up to 1, while FA-10 tends to reach a BWI value just below 0.8. Interestingly, BWI values of FA seems to be rather close to OPC even after 600 minutes. The drop in BWI for FA-10 when compared with IP-10 infers that grinding of volcanic ash retards the hydration; thus indicating finer the ash, the slower the setting time 
during hydration. The difference in tapering in the diffusion limited zone is an indication of retardation of nucleation and growth and this tapering increases with the particle size. The differences between IP-50 and FA-50 were not as significant as compared to IP-10 and FA-10. As seen in previous studies the hydration kinetics depend on the effect of particle size and interpretation of the data can be challenging $[7,13,14,19]$. The difference in BWI could be attributed to several factors such as volume of the material available for hydration, amount of surface area exposed to hydration, amount of hydration products present in amorphous form and possible decalcification of C-S-H.

$\mathrm{C}-\mathrm{S}-\mathrm{H}$ decalcification is attributed to presence of unreacted $\mathrm{Mg}$ from the ash along with its interaction with Magnesium-Silicate-Hydrate (M-S-H) phase, which is commonly observed in cements prepared with pozzolanic volcanic ash $[3,8,41]$. The steady decrease in BWI for IP-50 after 700 minutes is influenced by higher amounts of $\mathrm{Mg}$ that could impact the nucleation and growth process as seen in previous studies $[13,42,43]$. With the addition of volcanic ash from 10 to $50 \%$, the $\mathrm{MgO}$ content is increased and studies show that $\mathrm{MgO}$ (also known as periclase) does not get immediately involved in the hydration process [38]. Addition of high $\mathrm{MgO}$ can retard the hydration process since the solubility $\mathrm{Mg}(\mathrm{OH})_{2}$ is far less than $\mathrm{Ca}(\mathrm{OH})_{2}$ and $\mathrm{MgO}$ hydrates in high alkali environment which precipitates to form miniature crystals of cement of $\mathrm{M}-\mathrm{S}-\mathrm{H}$, which further retards the hydration process [44]. Also, $\mathrm{MgO}$ hydrates very slowly and the conversion of $\mathrm{MgO}$ to $\mathrm{Mg}(\mathrm{OH})_{2}$ could create internal stresses causing expansion and degradation of the material[45].

Furthermore, the domain of induction or dormant period along with the nucleation and growth of hydration products do not rely on the particle size distribution [18]. On the contrary, the diffusion 
limited rate of hydration and the amount of hydration products formed are dependent on the chemical concentration of the precursor such as the volcanic ash that was used in the current work. An increase in BWI with time is attributed to higher formation of chemically combined water which is influenced by the particle size of the volcanic ash along with the interaction between the phases (C-S-H/C-A-S-H and M-S-H) that are formed due to the addition of volcanic ash [3]. In addition, hydrated aluminate sulfate phase inter-bound with water which is commonly found in calcium sulfoaluminate cements can also lead to rapid increase in observed BWI with curing time $[17,38,46]$. As the time for hydration continues the difference in BWI increases sharply after 500 minutes between OPC, IP-10, FA-10 and IP-50, FA-50. It is interesting to note that higher ash compositions (i.e. FA-50 and IP-50) show considerably lower BWI values in comparison to pure OPC and the lower ash concentration FA-10 and IP-10. Furthermore, addition of volcanic ash to Portland cement leads to multi-component phase formation with each phase reacting at different rates along with morphological differences in C-S-H [3, 47, 48]. Additional studies are further required using differential thermal calorimetry to understand the degree of reaction and to relate the degree of reaction to BWI. However, our results clearly show the effect of both particle size and volcanic ash replacement, with the concentration of volcanic ash being the greater contributor to BWI.

The HWHM of a broad Lorentzian can be fitted to a rapid jump diffusion model which is given by $[30,49,50]$,

$$
\mathrm{HWHM}=\hbar \frac{\mathrm{D}_{\mathrm{t}} \mathrm{Q}^{2}}{1+\mathrm{D}_{\mathrm{t}} \mathrm{Q}^{2}} \text { and } \mathrm{D}_{\mathrm{t}}=\frac{\mathrm{L}^{2}}{6 \tau_{0}}
$$

where $\mathrm{D}_{\mathrm{t}}=$ self-diffusion coefficient, $\hbar=$ Planck constant, $\mathrm{L}=$ mean jump distance, and $\tau_{0}$ is the average residence time between the jumps of water molecules. The HWHM of the bulk water 
component versus $\mathrm{Q}^{2}$ for IP-10, IP-50, FA-10, FA-50 and OPC after 15 hours of hydration is shown in Figure 5. For the sake of clarity only fitted curves are shown. The larger energy window from DCS allows tracking of the diffusion of water to larger Q values, while HFBS allowed the tracking of broadening of water molecules at lower Q values during the hydration process. For Figure 5, the $\mathrm{Q}^{2}$ values up to 0.4 originate from fitting the HFBS data and the rest of the values are from DCS data. After 15 hours of hydration, the HWHM is higher for IP-50 and FA-50, while it is smaller for IP-10 and FA-10 when compared to OPC. In addition, the observed increase in intensity of HWHM is associated with the presence of more free and mobile water in the pores and thus facilitating less bound and immobile water to be constrained in the hydration products

Using Figure 5 and from Eqn. 3 residence time and diffusion coefficients were extracted and are plotted at different times of curing. Our data shows that after 15 hours of hydration IP-50 and FA-50 showed smaller residence times $(\mathrm{FA}-50=184 \mathrm{ps}$ and IP-50 $=218 \mathrm{ps}$ ) in comparison to IP-10 and FA-10 (see Figure 6). These results clearly show that in case of IP-50 the water molecules reside in a position only for around 200 ps before they jump to nearby available site compared to OPC and IP-10 sample that is more restricted and resides about 3-to-4 times longer. For reference, the FA-10 and IP-10 data showed residence times of $572 \mathrm{ps}$ and $728 \mathrm{ps}$, respectively after 15 hours of hydration. In combination with lower BWI values for IP-50 and FA-50, this data suggests that higher amounts of free water are present in IP-50 and FA-50 indicating that $50 \%$ volcanic ash can lead to delayed setting and less amount of chemically bound water as compared to the cements prepared with $10 \%$ volcanic ash content. These results also suggest that there is an optimum limit for substitution of Portland cement with volcanic ash and amount of volcanic ash content has a greater effect than particle size of the ash suggesting various multi-microstructural 
phase compositions are formed by varying the volcanic ash composition in the mix. Effective usage of volcanic ash will rely on the pozzolanic reaction of the ash with the calcium hydroxide inside the pore solution.
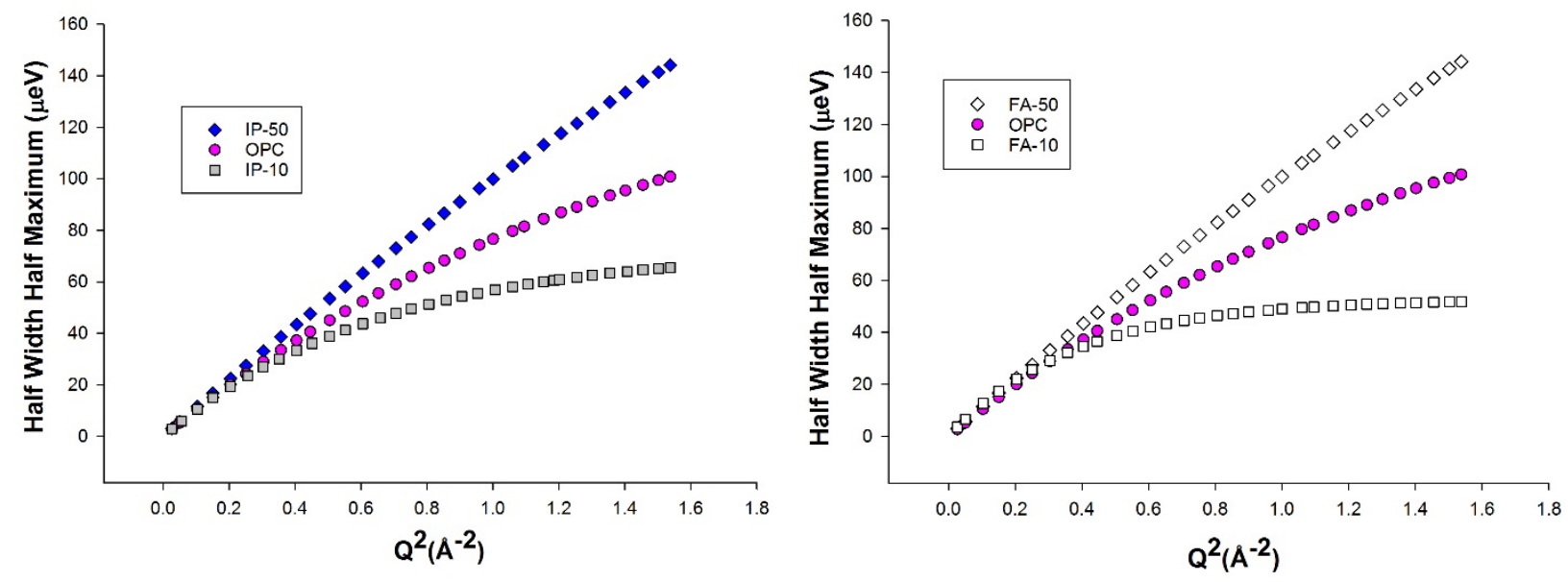

A

B

Fig 5. Half width half maximum (HWHM) as a function of $\mathrm{Q}^{2}$ for IP (Fig 5A) and FA (Fig. 5B) 10,50 and $\mathrm{OPC}$ after 15 hours of hydration
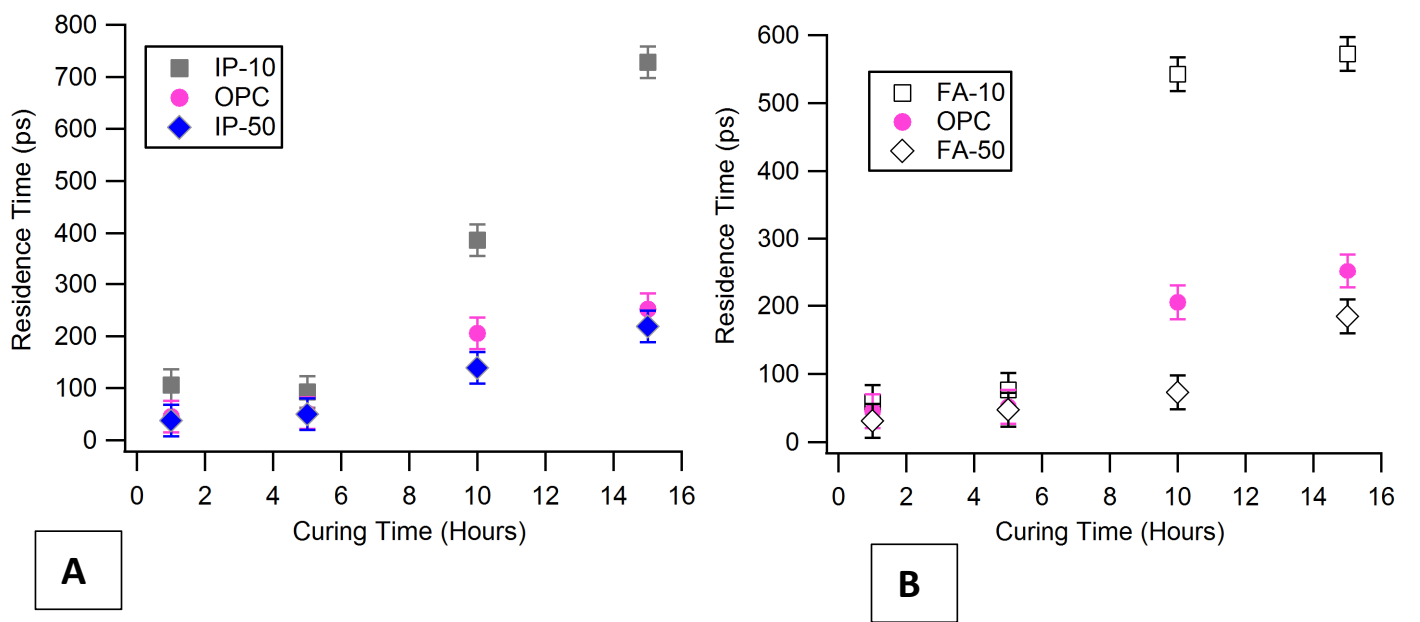

Fig 6. Plot of Residence time, $\tau_{0}$ versus time of curing for IP-10, IP-50 and OPC (A), FA-10, OPC and FA-50 (B).

Self-diffusion coefficients and mean jump distance (L) were also extracted from the hourly data as shown in Figure 7 and 8, respectively. For the sake of clarity the self-diffusion coefficients of 
IP and FA combinations are plotted separately with OPC (See Figure 7). As the hydration time increased a decrease in self-diffusion coefficient was detected for all the samples. It is interesting to note that diffusion of water slows down by almost an order irrespective of ash size or concentration within 15 hours of measurements. Changes in diffusion coefficients are commonly observed during hydration of cement paste and have been related to the evolution of multicomponents in cementitious gels (C-S-H, C-A-S-H), which possess different morphological features that are attributed to different relaxation times observed via NMR studies [51]. The effect of concentration can clearly be seen after the first one hour of hydration, IP-10 showing the lowest value of diffusion coefficient $\left(1.32 \times 10^{-9} \mathrm{~m}^{2} / \mathrm{sec}\right)$, while IP-50 exhibited the highest value $\left(4.65 \times 10^{-9} \mathrm{~m}^{2} / \mathrm{sec}\right)$. After 15 hours of hydration, diffusion coefficients of IP-50 and IP-10 were higher by a factor of 1.8 and 1.3 compared to FA-50 and FA-10, respectively. Furthermore, we also see the effect of particle size by comparing IP-50 and FA-50 after 10 hours than for lower replaced combination (IP-10 and FA-10) and interestingly we found larger effect for particle size is observed between 4-6 hours of hydration. On the other hand, after 7 hours of hydration no significant difference was observed among IP-10, FA-10 and OPC combinations. This suggests that finer the particle size of ash, it facilitates greater incorporation of volcanic ash to achieve more tortuous matrix with lower diffusion coefficients. Also, higher tortuosity leads to OH'units and interlayer water inside the C-S-H gel along with the formation of gel pores that facilities formation of bound water leading to slower diffusion coefficients. Prior studies show that finer particle size leads to an increase in hydration rate forming C-S-H product volume that results from nucleation and growth processes $[18,52]$. Furthermore, this work also indicates that the concentration of volcanic ash substitution has significant effect compared to the particle size of the ash; therefore 
concentration should be a major parameter when design cement pastes prepared with pozzolanic volcanic ash.

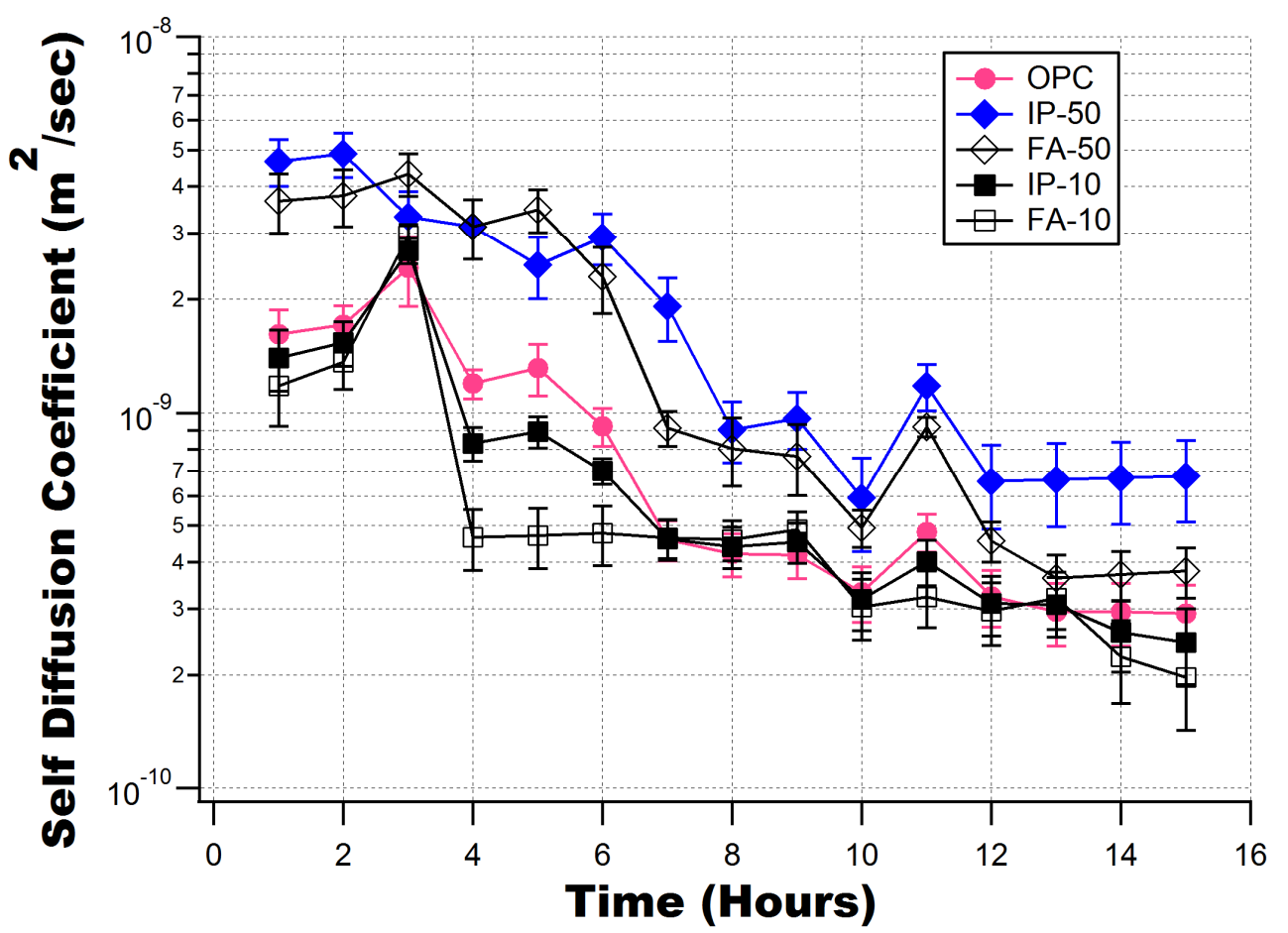

Fig 7. Self-diffusion coefficients in hydrating cement with combinations of $17 \mu \mathrm{m}$ (IP) and 14 $\mu \mathrm{m}$ (FA) volcanic ash along with Ordinary Portland Cement (OPC).

The mean jump distance, $\mathrm{L}$ for OPC, OPC-IP and OPC-FA cement paste combinations is shown in Figure 8. During the first four hours, all specimens showed relatively larger mean jump distances that suggest a local tetrahedral arrangement of the water molecule. It is also observed that finer ash/Portland cement combinations produced lower $\mathrm{L}$ values with the increase in the age of curing. This indicates that for finer ash/Portland cement combinations (FA-10 and IP-10) the mobile water becomes somewhat more restricted due to its presence in the smaller gel pores. Furthermore, for the first seven hours faster decrease in jump length was observed with time in IP50 and FA-50 samples as compared to OPC, IP-10 and FA-10, suggesting that all the volcanic ash was not involved in the hydration reaction retaining bulk water like properties. This also indicates that higher volcanic ash content, less OPC to participate in the reaction therefore greater the 
capacity to retain the water. Additionally, the unreacted volcanic ash in IP and FA-50 can occupy mobile water during hydration and the mobile water becomes trapped inside the unreacted volcanic ash. On the contrary, IP-10, FA-10 and OPC showed similar decrease in jump length with time throughout the hydration process facilitating higher homogenized hydration. This results show that lower volcanic ash substitution to Portland cement has greater impact on hydration than the particle size. Thus, the optimum limit for substitution of volcanic ash to Portland cement should be based on volcanic ash composition and not particle size. Additional studies containing more volcanic ash/Portland cement combinations between 10 and $50 \%$ are required to estimate an optimum limit for developing homogenized and durable cementitious matrix.

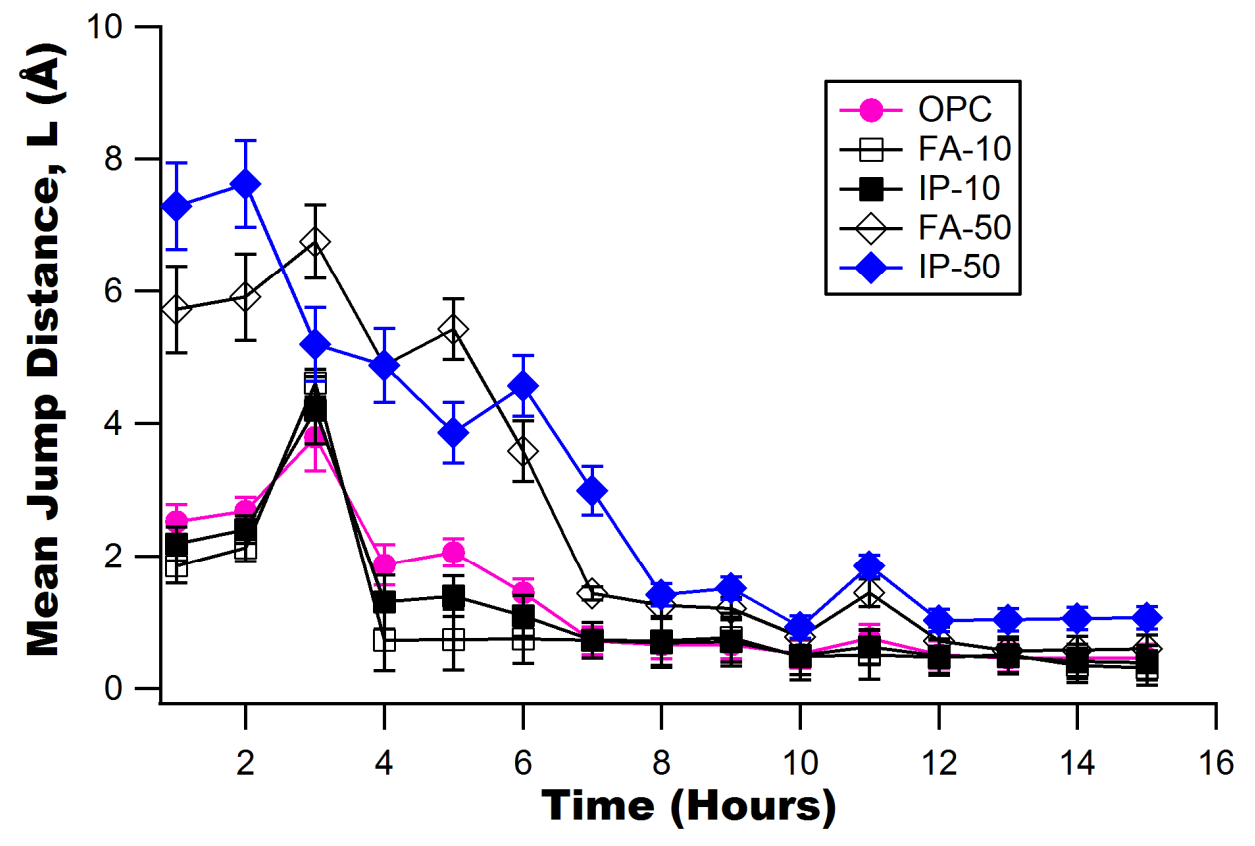

Fig 8. Time evolution of mean jump distance, $\mathrm{L}$ of hydrating cement with combinations of 17 $\mu \mathrm{m}$ (IP) and $14 \mu \mathrm{m}$ (FA) volcanic ash along with ordinary Portland cement (OPC).

\section{Conclusion}

QENS was used to monitor the early age hydration of Portland cements with volcanic ash. In this work, volcanic ash consisting of two different particle sizes with mean diameters of $14 \mu \mathrm{m}$ and 17 
$\mu \mathrm{m}$ were used to prepare cement paste containing Portland cements and volcanic ash. The translational dynamics of water contained in OPC pastes with and without volcanic ash for a setting time of 15 hours was studied and the influence of particle size of the volcanic ash on hydration was examined. The parameters extracted from QENS data were BWI, self-diffusion coefficients, and mean jump distance with varying time of hydration. Finer particle size and lower concentration of substitution of OPC with volcanic ash produced higher BWI value, self-diffusion coefficients and mean jump distances indicating higher amounts of bound immobile water component during the hydration process. Increase in concentration of the volcanic ash affected the hydration by allowing more free and mobile water in the gel pores suggesting that volcanic ash may not have completely been involved in the hydration process. Thus, this work shows that volcanic ash substitution has greater effect than particle size and governs the early age of the hydration process indicating an optimum limit for substituting Portland cements with volcanic ash.

\section{Acknowledgement}

This work utilized facilities supported in part by the National Science Foundation under Agreement No. DMR-0944772. We thank the "Kuwait Foundation for the Advancement of Sciences" and "Kuwait-MIT Center for Natural Resources and the Environment" for the support during this work. We also acknowledge fruitful discussion with Dr. Andrew Allen from the Materials Structure and Data Group in the Materials Measurement Science Division at NIST.

\section{References}

[1] P.C. Aïtcin, S. Mindess, Sustainability of Concrete, Taylor \& Francis, 2011.

[2] B. Lothenbach, K. Scrivener, R.D. Hooton, Supplementary cementitious materials, Cement and Concrete Research, 41 (2011) 1244-1256.

[3] K. Celik, M.D. Jackson, M. Mancio, C. Meral, A.H. Emwas, P.K. Mehta, P.J.M. Monteiro, High-volume natural volcanic pozzolan and limestone powder as partial replacements for portland cement in selfcompacting and sustainable concrete, Cement and Concrete Composites, 45 (2014) 136-147. 
[4] M. Jackson, G. Vola, D. Všianský, J. Oleson, B. Scheetz, C. Brandon, R. Hohlfelder, Cement Microstructures and Durability in Ancient Roman Seawater Concretes, in: J. Válek, J.J. Hughes, C.J.W.P. Groot (Eds.) Historic Mortars, Springer Netherlands, 2012, pp. 49-76.

[5] E. Gotti, J. Oleson, L. Bottalico, C. Brandon, R. Cucitore, R. Hohlfelder, A COMPARISON OF THE CHEMICAL AND ENGINEERING CHARACTERISTICS OF ANCIENT ROMAN HYDRAULIC CONCRETE WITH A MODERN REPRODUCTION OF VITRUVIAN HYDRAULIC CONCRETE*, Archaeometry, 50 (2008) 576-590.

[6] P. Hewlett, Lea's Chemistry of Cement and Concrete, Elsevier Science, 2003.

[7] V. Peterson, Studying the Hydration of Cement Systems in Real-time Using Quasielastic and Inelastic Neutron Scattering, in: G. Eckold, H. Schober, S.E. Nagler (Eds.) Studying Kinetics with Neutrons, Springer Berlin Heidelberg, 2010, pp. 19-75.

[8] K. Kupwade-Patil, S. Palkovic, S. Pirzadeh-Harisy, A. Bumajdad, C. Hoyuelos, O. Buyukozturk, Examination of pore and microstructure in hardened cement pastes prepared with natural volcanic ash, silica fume and Ordinary Portland Cement, Cement and Concrete Composites, (2015).

[9] V.S. Ramachandran, J.J. Beaudoin, Handbook of Analytical Techniques in Concrete Science and Technology: Principles, Techniques and Applications, Elsevier Science, 2000.

[10] A. Valori, P.J. McDonald, K.L. Scrivener, The morphology of C-S-H: Lessons from $1 \mathrm{H}$ nuclear magnetic resonance relaxometry, Cement and Concrete Research, 49 (2013) 65-81.

[11] A.C.A. Muller, J. Mitchell, P.J. McDonald, Proton nuclear magnetic resonance relaxometry, in: K. Scrivener, R. Snellings, B. Lothenbach (Eds.) A Practical Guide to Microstructural Analysis of Cementitious Materials, CRC Press, Boca Raton, FL, 2016, pp. 287-349.

[12] A. Faraone, E. Fratini, P. Baglioni, S.-H. Chen, Quasielastic and inelastic neutron scattering on hydrated calcium silicate pastes, The Journal of Chemical Physics, 121 (2004) 3212-3220.

[13] V.K. Peterson, C.M. Brown, R.A. Livingston, Quasielastic and inelastic neutron scattering study of the hydration of monoclinic and triclinic tricalcium silicate, Chemical Physics, 326 (2006) 381-389.

[14] V.K. Peterson, D.A. Neumann, R.A. Livingston, Inelastic neutron scattering investigation of hydrating tricalcium and dicalcium silicate mixture pastes: $\mathrm{Ca}(\mathrm{OH}) 2$ formation and evolution of strength, Journal of Materials Research, 21 (2006) 1836-1842.

[15] R. Berliner, M. Popovici, K.W. Herwig, M. Berliner, H.M. Jennings, J.J. Thomas, Quasielastic Neutron Scattering Study of the Effect of Water-to-Cement Ratio on the Hydration Kinetics of Tricalcium Silicate, Cement and Concrete Research, 28 (1998) 231-243.

[16] M.B. Pinson, E. Masoero, P.A. Bonnaud, H. Manzano, Q. Ji, S. Yip, J.J. Thomas, M.Z. Bazant, K.J. Van Vliet, H.M. Jennings, Hysteresis from Multiscale Porosity: Modeling Water Sorption and Shrinkage in Cement Paste, Physical Review Applied, 3 (2015) 064009.

[17] J.J. Thomas, S.A. FitzGerald, D.A. Neumann, R.A. Livingston, State of Water in Hydrating Tricalcium Silicate and Portland Cement Pastes as Measured by Quasi-Elastic Neutron Scattering, Journal of the American Ceramic Society, 84 (2001) 1811-1816.

[18] A.J. Allen, J.C. McLaughlin, D.A. Neumann, R.A. Livingston, In situ quasi-elastic scattering characterization of particle size effects on the hydration of tricalcium silicate, Journal of Materials Research, 19 (2004) 3242-3254.

[19] V.K. Peterson, D.A. Neumann, R.A. Livingston, Hydration of Tricalcium and Dicalcium Silicate Mixtures Studied Using Quasielastic Neutron Scattering, The Journal of Physical Chemistry B, 109 (2005) 1444914453.

[20] E. Fratini, A. Faraone, F. Ridi, S.-H. Chen, P. Baglioni, Hydration Water Dynamics in Tricalcium Silicate Pastes by Time-Resolved Incoherent Elastic Neutron Scattering, The Journal of Physical Chemistry C, 117 (2013) 7358-7364.

[21] H.N. Bordallo, L.P. Aldridge, A. Desmedt, Water Dynamics in Hardened Ordinary Portland Cement Paste or Concrete: From Quasielastic Neutron Scattering, The Journal of Physical Chemistry B, 110 (2006) 17966-17976. 
[22] T. Gutberlet, H. Hilbig, R.E. Beddoe, W. Lohstroh, New insights into water bonding during early tricalcium silicate hydration with quasielastic neutron scattering, Cement and Concrete Research, 51 (2013) 104-108.

[23] J.W. Phair, J.C. Schulz, W.K. Bertram, L.P. Aldridge, Investigation of the microstructure of alkaliactivated cements by neutron scattering, Cement and Concrete Research, 33 (2003) 1811-1824.

[24] H.N. Bordallo, L.P. Aldridge, P. Fouquet, L.C. Pardo, T. Unruh, J. Wuttke, F. Yokaichiya, Hindered Water Motions in Hardened Cement Pastes Investigated over Broad Time and Length Scales, ACS Applied Materials \& Interfaces, 1 (2009) 2154-2162.

[25] S.A. FitzGerald, D.A. Neumann, J.J. Rush, D.P. Bentz, R.A. Livingston, In Situ Quasi-elastic Neutron Scattering Study of the Hydration of Tricalcium Silicate, Chemistry of Materials, 10 (1998) 397-402.

[26] E. Fratini, S.-H. Chen, P. Baglioni, Investigation of the Temporal Evolution of Translational Dynamics of Water Molecules in Hydrated Calcium Aluminate Pastes, The Journal of Physical Chemistry B, 107 (2003) 10057-10062.

[27] E. Fratini, S.-H. Chen, P. Baglioni, M.-C. Bellissent-Funel, Quasi-Elastic Neutron Scattering Study of Translational Dynamics of Hydration Water in Tricalcium Silicate, The Journal of Physical Chemistry B, 106 (2001) 158-166.

[28] J.W. Phair, R.A. Livingston, C.M. Brown, A.J. Benesi, Investigation of the State of Water in Hydrating Layered Sodium Disilicate in Crystalline and Amorphous Forms by Quasi-Elastic Neutron Scattering, Chemistry of Materials, 16 (2004) 5042-5050.

[29] F. Ridi, P. Luciani, E. Fratini, P. Baglioni, Water Confined in Cement Pastes as a Probe of Cement Microstructure Evolution, The Journal of Physical Chemistry B, 113 (2009) 3080-3087.

[30] H. Li, L.-L. Zhang, Z. Yi, E. Fratini, P. Baglioni, S.-H. Chen, Translational and rotational dynamics of water contained in aged Portland cement pastes studied by quasi-elastic neutron scattering, Journal of Colloid and Interface Science, 452 (2015) 2-7.

[31] A. Goldman, A. Bentur, Bond effects in high-strength silica-fume concretes, ACI Materials Journal, 86 (1989) 440-447.

[32] K.L. Scrivener, A. Bentur, P.L. Pratt, Quantitative characterization of the transition zone in high strength concretes, Advances in Cement Research, 1 (1988) 230-237.

[33] D. Hou, Z. Li, T. Zhao, P. Zhang, Water transport in the nano-pore of the calcium silicate phase: reactivity, structure and dynamics, Physical Chemistry Chemical Physics, 17 (2015) 1411-1423.

[34] ASTM, Standard Specification for Coal Fly Ash and Raw or Calcined Natural Pozzolan for Use in Concrete, in: ASTM C 618-12a, ASTM International, West Conshohocken, 2004.

[35] A. Meyer, R.M. Dimeo, P.M. Gehring, D.A. Neumann, The high-flux backscattering spectrometer at the NIST Center for Neutron Research, Review of Scientific Instruments, 74 (2003) 2759-2777.

[36] J.C. Cook, J.R.D. Copley, Simulations and measurements of the performance of a channeled neutron guide for a time-of-flight spectrometer at the NIST Center for Neutron Research, Review of Scientific Instruments, 75 (2004) 430-439.

[37] R.T. Azuah, L.R. Kneller, Y. Qiu, P.L.W. Tregenna-Piggott, C.M. Brown, J.R.D. Copley, R.M. Dimeo, DAVE: A comprehensive software suite for the reduction, visualization, and analysis of low energy neutron spectroscopic data, Journal of Research of the National Institute of Standards and Technology, 114 (2009) 341-358.

[38] I. Odler, Special Inorganic Cements, Taylor \& Francis, 2003.

[39] W. Bumrongjaroen, R.A. Livingston, D.A. Neumann, A.J. Allen, Characterization of fly ash reactivity in hydrating cement by neutron scattering, Journal of Materials Research, 24 (2009) 2435-2448.

[40] R. Berliner, M. Popovici, K. Herwig, H.M. Jennings, J. Thomas, Neutron scattering studies of hydrating cement pastes, Physica B: Condensed Matter, 241-243 (1997) 1237-1239. 
[41] K. Kupwade-Patil, A.F. Al-Aibani, M.F. Abdulsalam, C. Mao, A. Bumajdad, S.D. Palkovic, O. Büyüköztürk, Microstructure of cement paste with natural pozzolanic volcanic ash and Portland cement at different stages of curing, Construction and Building Materials, 113 (2016) 423-441.

[42] G. Mascolo, V.S. Ramachandran, Hydration and strength characteristics of synthetic Al-, Mg- and Fe alites, Mat Constr, 8 (1975) 373-376.

[43] D. Bonen, Composition and Appearance of Magnesium Silicate Hydrate and Its Relation to Deterioration of Cement-Based Materials, Journal of the American Ceramic Society, 75 (1992) 2904-2906. [44] L. Zheng, C. Xuehua, T. Mingshu, Hydration and setting time of MgO-type expansive cement, Cement and Concrete Research, 22 (1992) 1-5.

[45] V. Ramachandran, Unsoundness of cements containing MgO and CaO, Cemento, 77 (1980) 159-168. [46] H.F.W. Taylor, Cement Chemistry, Second Edition, Thomas Telford, 1997.

[47] K.M.A. Hossain, M. Lachemi, Performance of volcanic ash and pumice based blended cement concrete in mixed sulfate environment, Cement and Concrete Research, 36 (2006) 1123-1133.

[48] E. Liebig, E. Althaus, Pozzolanic Activity of Volcanic Tuff and Suevite: Effects of Calcination, Cement and Concrete Research, 28 (1998) 567-575.

[49] M. Bée, Quasielastic Neutron Scattering, Adam Hilger, 1988.

[50] K.S. Singwi, A. Sjölander, Diffusive Motions in Water and Cold Neutron Scattering, Physical Review, 119 (1960) 863-871.

[51] N. Nestle, P. Galvosas, O. Geier, C. Zimmermann, M. Dakkouri, J. Kärger, Nuclear magnetic resonance study of diffusion and relaxation in hydrating white cement pastes of different water content, Journal of Applied Physics, 89 (2001) 8061-8065.

[52] J.J. Thomas, H.M. Jennings, A.J. Allen, The surface area of cement paste as measured by neutron scattering: evidence for two C-S-H morphologies, Cement and Concrete Research, 28 (1998) 897-905. 


\section{Nomenclature}

\begin{tabular}{|c|c|}
\hline$\hbar$ & : Planck constant, \\
\hline$\tau_{0}$ & : Average residence time between the jumps of water molecules. \\
\hline A & : Scattered elastic intensity associated the chemically bound (CB) hydrogen \\
\hline $\mathrm{B}_{1}$ & : Number density of free hydrogen atoms as in the bulk water \\
\hline $\mathrm{B}_{2}$ & : Number density of hydrogen atoms in pseudo-bound or constrained form of water \\
\hline BWI & : Bound Water Index \\
\hline $\mathrm{C}_{0}$ & : Fixed baseline intensity \\
\hline $\mathrm{C}_{3} \mathrm{~S}$ & : Tri Calcium Silicate \\
\hline C-A-S-H & : Calcium-Alumino-Silicate-Hydrate \\
\hline $\mathrm{C}-\mathrm{S}-\mathrm{H}$ & : Calcium Silicate Hydrate \\
\hline DAVE & : Data Analysis and Visualization Environment \\
\hline DCS & : Disk Chopper Spectrometer \\
\hline DSC & : Differential Scanning Calorimetry \\
\hline $\mathrm{D}_{\mathrm{t}}$ & : Self-Diffusion Coefficient \\
\hline FA & : Cement pastes prepared with $14 \mu \mathrm{m}$ volcanic ash \\
\hline FWHM & : Full Width Half Maximum \\
\hline GGBFS & : Ground Granulated Blast Furnace Slag \\
\hline HFBS & : High Flux Backscattering Spectrometer \\
\hline HWHM & : Half Width Half Maximum \\
\hline INS & : Inelastic Neutron Scattering \\
\hline IP & : Cement pastes prepared with $17 \mu \mathrm{m}$ volcanic ash \\
\hline $\mathrm{L}$ & : Mean jump distance \\
\hline M-S-H & : Magnesium-Silicate-Hydrate \\
\hline NMR & : Nuclear Magnetic Resonance \\
\hline OPC & : Ordinary Portland Cement \\
\hline$Q$ & : Scattering vector \\
\hline QENS & : Quasi Elastic Neutron Scattering \\
\hline $\mathrm{R}(Q, \omega)$ & : Instrument resolution for which a vanadium standard was used \\
\hline $\mathrm{S}(Q, \omega)$ & : Function of $Q$ and energy transfer, $\omega$ \\
\hline SANS & : Small Angle Neutron Scattering \\
\hline VA & : Volcanic Ash \\
\hline $\mathrm{XRF}$ & : X-Ray Fluorescence \\
\hline$\Gamma_{1}$ & : Lorentzian half-width at half maximum for the bulk water component \\
\hline$\Gamma_{2}$ & : Second Lorentzian with the variable Half Width Half Maximum fitting parameter \\
\hline
\end{tabular}

